\title{
One-step Hydrothermal Synthesis of Amorphous Nickel/Iron Oxide and its Application as Catalyst for Efficient Oxygen Evolution Reaction
}

\author{
Yunfei Li ${ }^{1,2}$, Yuanfeng Gao ${ }^{1,2}$, Meitang Liu ${ }^{1,2, *}$, Tianlei Wang ${ }^{3}$, Xu Wang ${ }^{1,2}$, Haisheng Hu ${ }^{1,2}$ \\ ${ }^{1}$ Beijing Key Laboratory of Materials Utilization of Nonmetallic Minerals and Solid Wastes, PR \\ China. \\ ${ }^{2}$ School of Materials Science and Technology, China University of Geosciences, Beijing, 100083, PR \\ China. \\ ${ }^{3}$ School of Materials Science and Engineering, Tianjin Chengjian University, Tianjin 300384, China \\ "E-mail: Mtliu@cugb.edu.cn.
}

Received: 8 December 2021 / Accepted: 11 January 2022 / Published: 2 February 2022

It is of great significance to explore low-cost and high-efficiency oxygen evolution reaction electrocatalysts to meet the challenges of sustainable energy development. In this paper, amorphous nickel-iron oxide was successfully synthesized via a simple one-step hydrothermal method with the help of citric acid-sodium citrate buffer solution and template CTAB. Excellent dispersion and porous structure were found for the obtained samples, which significantly increase the exposed surface area of active sites of the catalyst. In addition, the morphology of Ni-Fe oxides could be controlled and the electronic structure of $\mathrm{Ni}$ could be modified by changing $\mathrm{Ni} / \mathrm{Fe}$ mole ratio. When $\mathrm{Ni} / \mathrm{Fe}$ mol ratio equals 3:1, this material exhibits the best catalytic activity, with an overpotential of only $197 \mathrm{mV}$ at the current density of $10 \mathrm{~mA} \mathrm{~cm}^{-2}$ and Tafel slope of $39 \mathrm{mV} \mathrm{dec}^{-1}$. Thus, this work provides an economical way to prepare efficient electrocatalysts based on transition metal elements.

Keywords: $\mathrm{Ni}_{\mathrm{x}} \mathrm{Fe}_{1}$ oxide, Amorphous, Oxygen evolution reaction, Hydrothermal

\section{$\underline{\text { FULL TEXT }}$}

(C) 2022 The Authors. Published by ESG (www.electrochemsci.org). This article is an open access article distributed under the terms and conditions of the Creative Commons Attribution license (http://creativecommons.org/licenses/by/4.0/). 